\title{
A morte da biblioteca? 0 lugar do livro e do leitor na era da dispersão
}

\author{
JOACI PEREIRA FURTADO
}

\section{Resumo}

Com a imaterialidade do livro, qual o lugar dele na sociedade contemporânea? A biblioteca, como repositório de livros, faz sentido quando a palavra escrita se tornou ubíqua e virtualmente passível de ser lida em qualquer ponto do planeta? Se o livro existe como tal somente quando é lido, que significado tem a leitura hoje? 


\title{
The death of the library? The place of the book and the reader at the time of dispersion
}

\author{
JOACI PEREIRA FURTADO
}

\begin{abstract}
With the immateriality of the book, which is its place in contemporary society? Does the library, as a repository of books make sense when the word became ubiquitous and virtually capable of being read at any point on earth? If the book exists as such only when it is read, what does it mean the reading today?
\end{abstract}




\title{
¿La muerte de la biblioteca? El lugar del libro y del lector en la era de la dispersión
}

\author{
JOACI PEREIRA FURTADO
}

\section{Resumen}

Con la inmaterialidad del libro, ¿cuál el lugar del en la sociedad contemporánea? ¿La biblioteca, como repositorio de libros, haz sentido cuando la palabra escrita se ha tornado ubicua y virtualmente pasible de ser leída en cualquier punto del planeta? Si el libro existe solo cuando es leído, ¿qué significado tiene la lectura hoy? 


\section{À memória de Eduardo Murguia (1954-2015)}

No "Sermão da Primeira Dominga do Advento", pregado na Capela Real, em Lisboa, em 1650, diz o padre Antônio Vieira (2000, p. 374) sobre santos da Igreja que recusaram o lugar de bispo: "não quiseram subir à alteza da dignidade, porque reconheceram a do precipício”. Não fui tão prudente, ao aceitar o convite do querido amigo Samuel de Jesus, a quem muito agradeço, assim como à Faculdade de Artes Visuais da Universidade Federal de Goiás, que possibilitou minha presença aqui. Porque, embora lecione para o curso de biblioteconomia da Universidade Federal Fluminense, não me considero e nem sou um especialista na área. E, hoje, não ser especialista é dançar à beira do abismo. Mas, já que me lanço nele, gostaria de usufruir do único bem dos que se atiram voluntariamente num precipício: a liberdade de quem não tem mais o que perder, enquanto o fim da queda não chega. É exatamente no instante dessa queda que gostaria de situar minha fala, pois ela está livre de qualquer pretensão conclusiva, prescritiva ou exaustiva sobre a matéria que eu mesmo me propus, inspirado pelo tema deste seminário: "Arquivos, memórias, afetos". Tenho mais dúvidas, indagações e angústias a somar do que certezas a dividir. E algumas ideias a multiplicar, com a ajuda dos que me concederem o favor de sua companhia.

Começaria dizendo que, quando falamos em livro, pensamos numa forma. Quando pensamos nessa forma, nos remetemos a um espaço. E quando nos remetemos a esse espaço, nos referimos à biblioteca. Mas, com certeza, vocês me diriam que essa equação é atualmente estúpida, pois ao menos desde a invenção do xerox o que chamamos de "livro" vem se dispersando em várias formas, até alcançar os diferentes suportes digitais de hoje. No século XXI, o velho formato codex inventado pelos 
latinos no século I d. C. convive com outros tantos, que tendem a suplantá-lo. Somos testemunhas de uma revolução mais radical que a invenção da imprensa, porque esta não alterou o formato milenar do livro - que agora pode ser lido em tablets, celulares, e-readers, notebooks, netbooks, telas de computadores e, claro, ainda em papel. De modo que, cada vez mais, a palavra "livro" remete a um conteúdo - e não a um objeto.

Se eu não me rendesse à força dos fatos, provavelmente vocês me proporiam o seguinte exercício: imaginar o que é possível fazer ou não com o livro eletrônico - ou e-book - a partir de nossa experiência com o livro impresso. Este, na paisagem urbana, está nas mãos dos que viajam de ônibus ou metrô, no colo do motorista que aproveita a lentidão do trânsito, no lazer de quem se acomoda no banco da praça ou no gramado do parque. Ele caracteriza o estudante e o professor, é inseparável do hare krishna e do evangélico, é brandido pelos revolucionários de Mao Tsé-Tung e Muammar Kadafi, é carregado solenemente em rituais judaicos e católicos, pesa na mesa do juiz e do gramático, já foi proibido e queimado por ditaduras e pela Inquisição. A ele são dedicados espaços públicos próprios, às vezes monumentais, assim como políticas de Estado que movimentam cifras astronômicas. Comercializado, para ele são desenvolvidas agressivas campanhas de marketing e propaganda, lojas sofisticadas e complexas, empresas que obedecem à lógica do mercado e a estratégias corporativas. Mas ele também pode ser doado, presenteado, emprestado - e nunca devolvido -, esquecido, abandonado, herdado, roubado, revendido, compartilhado, copiado à mão ou mecanicamente. Na intimidade, acalenta o sono e o imaginário de crianças, preenche o ócio de idosos, convalescentes e presidiários, jaz sobre o tampo de coffee tables e criados-mudos (ou sob a cama), abarrota estantes, acumula-se em pilhas empoeiradas pelos cantos da casa, envelhece e mofa sobre guarda-roupas ou em porões e caixas, é riscado e anotado pelo pesquisador, guarda cartões postais, bilhetes, dinheiro, recortes de jornal, o título de eleitor, a marca de uma lágrima. Com dimensões, pesos, cores, texturas, materiais e cheiros diferentes, é universalmente identificável. No imaginário coletivo, é tido como fonte de saber - quando não de sabedoria - e está inseparavelmente associado à certa noção de "cultura", mesmo entre aqueles que, apesar de alfabetizados, não lhe reservam sequer algumas horas por mês ou pela vida toda. De fato, embora muitas dessas práticas ou situações desapareçam com a xerox, o e-book, o pdf e a internet, chamamos de "livro" as partes ou a íntegra de textos digitalizados que lemos em telas ou em folhas de 
fotocópias. Os suportes eletrônicos conferiram uma ubiquidade inaudita à palavra escrita e estenderam a autonomia do leitor a limites antes inimagináveis, ao ponto de ele poder ser também coautor (FISCHER, 2006, p. 295). Mais que isso, agora o livro é pensável numa interação multimídia improvável até bem pouco tempo, não só mobilizando simultaneamente som e imagem em movimento (CHARTIER, 1998, p. 72-3), mas realizando na tela, por meio de hiperlinks, a labiríntica biblioteca de Babel imaginada por Jorge Luis Borges (1999, p. 516-23).

Implacáveis na desconstrução de meu enunciado, porém, talvez vocês me lembrassem ainda que a dispersão, a virtualização e a individualização do acesso ao livro esvaziaram ou ao menos redefiniram o sentido da biblioteca, cujo "paradigma da acumulação" foi instaurado em Alexandria, no Egito helenizado, no século III a. C. (BARATIN, 2000, p. 227-33). Esvaziaram não só esse paradigma, mas a própria ideia aristotélica de sunagagôn (coleção) de livros e suntaxin (ordenação) desses objetos descontextualizados e "reorganizados em catálogos temáticos, nos quais sua própria acumulação é produtora de sentido e oferece os materiais necessários para novas elaborações teóricas, históricas e políticas" (JACOB, 200o, p. 47). Virtualmente, hoje o "mundo inteiro é nossa livraria" (FISCHER, 2006, p. 281). A biblioteca, pois, não é mais o único ou o principal repositório de livros, revistas e jornais - e, portanto, de informação. Se agora a palavra "livro" nomeia um conteúdo e não uma forma, "biblioteca" designa uma função e não um espaço. Diante de meu ceticismo, vocês me remeteriam àquele artigo do historiador norte-americano Robert Darnton, publicado em 2001 no Brasil como "O poder das bibliotecas" e originariamente apresentado em 1999, como conferência na Biblioteca Pública de Nova York. No texto, Darnton se diz "horrorizado" ao saber que "o projeto original para um novo campus da Universidade da Califórnia em Monterey nem sequer incluía uma biblioteca" - já que, segundo os projetistas, "os computadores seriam suficientes", pois os livros nada mais seriam que "recipientes de informação" (DARNTON, 2001). Assim como o museu e o arquivo, a biblioteca não é mais o espaço exclusivo ou preferencial da memória coletiva, conforme instituído pelos Estados nacionais desde o século XIX inspirados no paradigma alexandrino. A internet, acessível de qualquer ponto do planeta onde o suporte eletrônico a conecte, é uma gigantesca geradora e acumuladora de documentos virtuais - e os mecanismos de busca, como o Google, um catálogo onde o consulente não mais pergunta "Você tem o que procuro?", mas exige: "Eu quero", e é atendido em milésimos de segundo." 
Diante desses argumentos, fica difícil insistir na assertiva inicial - a de que o livro é uma forma que ocupa um espaço e que este é socialmente delimitado ou identificável. Se for como vocês, com certeza, me convenceriam, restam algumas perguntas para as quais ando em busca de respostas - e que lhes lanço como desafio, já que são tão bons na argumentação.

A primeira delas certamente lhes interessa de imediato, pois diz respeito à forma na era digital. Haverá um design próprio, radicalmente outro para o livro eletrônico? Mais que design, haverá uma linguagem visual específica da tela, efetivamente diferente da página impressa? Ora, ou estou enganado ou o e-book é, ao menos em se tratando de prosa, basicamente a emulação virtual do livro impresso, por mais que o leitor possa intervir, alterando fontes, contrastes e dimensões, acrescentando comentários e anotações e saltando de uma página a outra com rapidez tão vertiginosamente instantânea, quanto naturalmente banalizada. Pode ser um sintoma do conservadorismo da indústria editorial do livro, pouco afeita a experimentações, que estejam no Kindle ou no Kobo as páginas que se sucedem como no codex latino, o parágrafo - invenção de escribas irlandeses do século IX (FISCHER, 2006, p. 148) -, a divisão em capítulos também inaugurada na Idade Média, as igualmente medievais capitulares, os princípios elementares da diagramação que o italiano Aldo Manuzio sistematizou no final do século XV, o menu com fontes tipográficas desenhadas por um Claude Garamond (14801561) ou um Gianbattista Bodoni (1740-1813), a folha de rosto ou frontispício, os rodapés, os sumários, a página de créditos, os eventuais prefácios ou posfácios, a capa e alguns outros aparatos que, com variações sutis, caracterizam o livro desde os tempos de Johannes Gutenberg. É provável, portanto, que continuemos a ler El ingenioso hidalgo Don Quixote de la Mancha e Memórias póstumas de Brás Cubas linha a linha, um parágrafo após outro, na sequência de seus respectivos capítulos, tal como essas obras foram pensadas e escritas em seus respectivos tempos. Em termos de forma, parece-me impossivel reiventá-los numa outra que não seja basicamente essa. A diferença é que talvez tenhamos cada vez menos leitores de Miguel de Cervantes e Machado de Assis. Mas para o Cervantes ou o Machado que por ventura esteja nascendo hoje, que forma ou formas a criação por meio da palavra escrita poderá assumir no ambiente digital? É certo que a criação poética, tão afeita a experimentalismos desde as vanguardas futuristas, vem testando esse suporte pelo menos desde os anos 1990 - e até já há estudiosos dessa poesia. ${ }^{2}$ Mas e a prosa ficcional? E a não ficcional? Num futuro quiçá nem tão distante 
escreveremos artigos, dissertações, teses e ensaios de um modo diferente, determinado por uma linguagem específica do digital? João Adolfo Hansen (2013, p. 21) nos antecipa uma possível resposta - ou vias para pensá-la:

As novas máquinas digitais de agora talvez sejam mais radicais que essas do século XIX e início do século XX porque não intervêm apenas em um campo parcial da atividade humana, como aconteceu nas artes plásticas e na literatura modernista e moderna, mas fazem redefinições radicais da totalidade do espaço-tempo do planeta, do corpo, do sujeito, das formas de sensibilidade, da política etc., fundamentais na invenção de novas formas de escrita e leitura.

Seja como for, quero crer que essas não são indagações ociosas. $\mathrm{O}$ futuro da biblioteca depende das respostas que dermos a elas - mas não só. De que essa instituição não é mais, por excelência, o lugar da memória - ou de certa memória, traduzida nisso que chamamos de literatura ou ciência ou filosofia ou história - vocês já teriam me convencido há um bom tempo. Porém, com a desmaterialização do livro, qual será o lugar dele e o que há de ser do seu lugar? Se desde o final do século passado é possível projetar câmpus universitário sem biblioteca, já podemos imaginar bibliotecas sem livros? A partir do que tenho lido, visto e conversado, sou levado a suspeitar que a resposta talvez não esteja no "onde" mas no "com quem" cabe o livro. Se ele existe como tal somente quando lido, se o livro se realiza apenas no ato de sua leitura, então me parece mais procedente pensar a relação que o leitor do século xxI estabelece com esse objeto, antes de nos resignarmos a atestar o óbito da biblioteca ou a adaptá-la ao novo leitor. Esse mesmo que se emancipou - ou foi excomungado - da liturgia do "templo do saber" para acessar o texto original de Crime e castigo ou o look das celebridades na revista Contigo!. Que ele, entre outras peculiaridades, é disperso e dispersivo, e que é pautado por uma indústria cultural reforçadora de consensos e inibidora da autonomia criativa, com certeza não resta dúvida. Mas constatar isso me parece insuficiente para caracterizá-lo e, sobretudo, para nos livrar do olhar censório, moralista e horrorizado com o consumo em larga escala da trilogia 50 tons de cinza e de livros para adultos colorirem.

Não é uma casualidade que, como lembra Alfredo Bosi, resgatando a etimologia do termo latino derivado do particípio passado do verbo colo, "cultura” signifique também “cultivo”, o trabalho sobre a terra, e "culto", o trabalho sob a terra - isto é, 
enterrar os mortos e honrar os antepassados (BOSI, 1993, p. 15). Trabalhar a terra pressupõe não só a invenção de técnicas e ferramentas para domesticar as plantas e intensificar a produção agrícola, mas a memória de procedimentos que se ritualizam ao longo do tempo, passando de geração a geração, durante centenas ou milhares de anos. Não há cultura, pois, sem repetição e transmissão, mesmo que nessa transmigração não deixe de atuar a transformação. Enquanto culto dos mortos, cultura significa respeitar "a alteridade das criaturas, pela sua transcendência, $o$ desejo de ultrapassar os confins do próprio ego, e vencer com as forças da alma as angústias da existência carnal a finita" (BOSI, 1993, p. 19). Por que com a leitura haveria de ser diferente? Enquanto prática cultural, ela não está divorciada das demais - e é preciso compreendê-la no âmbito do "inventar no cotidiano", isto é, da vasta e complexa "dimensão simbólica" de que fala Marilena Chauí (2012, p. 314). Em outras palavras, quiçá aqui mais pertinentes, "A leitura não é uma atividade isolada: ela encontra - ou deixa de encontrar - o seu lugar em um conjunto de atividades dotadas de sentido" (PETIT, 2013, p. 104).

Não me surpreende que a leitura - entendida como fruição daquilo que se lê espontaneamente - esteja banida do lazer da maioria dos brasileiros, ${ }^{4}$ pois ela foi deformada não somente, mas sobretudo pela escola, autora do tiro de misericórdia em todo e qualquer gozo com o prazer de ler ao tornar essa prática obrigatória e, pior, objeto de questionários e outras estratégias de intimidação pedagógica que "predeterminam a significação e o sentido dos textos, propondo-os como tendo uma verdade unívoca, acabada e fechada que deve ser parafraseada, pois não admite a produção de significações divergentes da que autorizam" (HANSEN, 2013, p. 48). Com a autonomia imaginativa sequestrada pela escola, que leitor poderá sobreviver a ela? Em outros termos, que significado a leitura pode ter na vida das pessoas se ela é uma antipática imposição institucional, que confina em cubículos classificatórios e interprativos "uma obra acabada sempre inacabada porque sempre aberta às iniciativas de leitores de diversas mediações sociais, dotados de competências culturais em diferentes situações sociais" (HANSEN, 2013, p. 37)? Não nos iludamos com a quimera iluminista de que basta a "magia do encontro" entre obra e público para que haja a imediata conversão dos "excluídos da cultura" à beleza revelada (BOTELHO, 2011, p. 9). Os critérios estéticos e a valoração do que é culturalmente relevante nada têm de natural (BOTELHO, 2011, p. 9) - esta parece ser a lição que a escola ainda não assimilou, enquanto que 
O marketing sabe agora que a industrialização da cultura prospera quando leva em conta as diferenças entre as nações e as etnias, entre homens e mulheres, quando se produzem bens diferentes para quem tem 6o, 40, 15 ou 8 anos. Custa às instituições governamentais dedicadas à difusão cultural admitir que sua tarefa de formar públicos deveria ir além de repetir a oferta para todos, divulgar palavras de ordem e cartazes, multiplicar bibliotecas públicas e escolas. Com fundos raquíticos, elas competem mal com as indústrias da comunicação, em vez de promover inovações, gerar, nos tempos longos da educação, experiências que levem ao desfrute tanto da arte como das novas linguagens. (GARCÍA, 20o8, p. 18)

Assim, minha hipótese é a de que, se não quiser insistir na postura suicida de apenas conservar acervos para um grupo cada vez menor de iniciados, a biblioteca terá que aprender a afetar a maioria dos que não querem ser seus frequentadores. Sem mobilizar seus afetos, é inócuo alardear que "ler é bom”. Cabe ao espaço da biblioteca efetivar essa bondade - ou poucos caberão com ela. Um exemplo talvez esclareça melhor o que quero lhes dizer. Na Biblioteca Central da Universidade Federal Fluminense, no câmpus de Gragoatá, no centro de Niterói, há um piano de cauda. Nas primeiras semanas como professor, no segundo semestre letivo de 2013, a princípio estranhei a inusitada presença do instrumento ali e, depois, admirei que ele estivesse sempre mudo, coberto, estacionado num canto do saguão do primeiro andar - o que me parecia absurdo desperdício. Soube mais tarde que, durante algum tempo, houve programação de apresentações semanais com o piano, na hora do almoço, quebrando por trinta minutos o rigoroso silêncio do ambiente. Nunca pude assistir aos recitais, mas escrevi à direção da biblioteca propondo ciclos temáticos de aulas-concerto para 2014, ano do vigésimo aniversário de inauguração do prédio da biblioteca - que, curiosamente, diga-se de passagem, tem paredes cegas para uma das vistas mais belas do mundo. Com gentis agradecimentos, a sugestão foi terminantemente recusada porque o instrumento "pertence ao Centro de Estudos em Iniciação Musical (CEIM) e será devolvido à Reitoria”. A resposta e a postura tipicamente burocráticas, cabais e sem margem para qualquer reconsideração, dão bem a medida da inépcia da biblioteca em lidar com o que escape à norma, à programação, ao procedimento, à rubrica, às finalidades do espaço, à competência da seção, à jurisdição do departamento, às funções 
do servidor, à dotação orçamentária e, em se tratando de uma universidade pública, à ausência de um projeto de extensão financiado pelo CNPq. Não deve causar espécie, pois, que a boa parte dos estudantes não encante a biblioteca, em particular, e a universidade como um todo - e que a batalha para que elas se constituam como alternativas à cultura de massa, se é que continua, esteja perdida há muito tempo: "Aí fora está muito mais interessante", vaticina a professora de uma escola pública de ensino médio da periferia paulistana no documentário Pro dia nascer feliz, dirigido por João Jardim. ${ }^{5}$ Ressignificar a biblioteca não é ideia minha e nem é nova: pelo menos desde os anos 1980 prescreve-se para ela, como condição de existência, tornar-se "casa da invenção" (MILANESI, 2003). Se há fórmulas para semelhante transformação, eu as ignoro, até por não crer em soluções prontas, alienadas de seu contexto, em se tratando de ação cultural. O que me parece indiscutível, porém, é que, em nossa contemporaneidade, a biblioteca fará sentido apenas se nos reconhecermos nela, se ela for capaz de acolher os que demandam alguma forma de autoconhecimento, de compreensão de seu próprio universo, de "encontrar palavras para não ser objeto de angústias incontroláveis" - porque "a descoberta de si e a descoberta do mundo caminham juntas” (PETIT, 213, p. 171).

Na antiga Alexandria, a biblioteca, consagrada ao deus Serápis, surge junto à Casa das Musas - o museu -, integrando o complexo palaciano de Ptolomeu Filadelfo (HANSEN, 2013, p. 26): ela é "um negócio de Estado, é posta sob o patrocínio do rei, que lhe assegura o funcionamento, lhe define a missão e lhe controla o acesso" (JACOB, 200o, p. 47). Porque a "memória escrita é uma herança de que é preciso apoderar-se, um ganho na rivalidade política das potências mediterrâneas" (JACOB, 200o, p. 48). A despeito ou justamente por isso, foi onde Erastóstenes calculou a circunferência da Terra, Hiparco "mapeou as constelações e estabeleceu a magnitude das estrelas", Euclides sistematizou a geometria, Dionísio da Trácia definiu as classes das palavras, Herófilo "afirmou ser o cérebro, e não o coração, a verdadeira sede da inteligência", Apolônio de Perga estudou a parábola e a elipse, Aristarco de Samos concluiu que nosso planeta gira em torno do sol - e não o contrário - e Hipácia, a primeira mulher cientista de que se tem registro, comentou a Aritmética de Diofanto e as Seções cônicas de Apolônio. De modo que, em seu tempo e lugar, a biblioteca de Alexandria fazia todo sentido: nela, "A perenidade das estrelas era questionada, a legitimidade da escravidão não era". ${ }^{6}$ Numa sociedade verdadeira 
ou supostamente democrática como a nossa, porém, essa instituição não deve se dar ao luxo de permanecer divorciada das questões de seu tempo. Se pode estar definitivamente morta para a estratégica centralidade científica de antes, a biblioteca hoje está livre para se reinventar como a ágora do mal-estar pós-moderno, da crise da representatividade, do apocalipse ambiental, das injustiças sociais e econômicas, da autonomia criativa, da liberdade de pensar, da leitura - que pode não se dar em livros impressos no milenar formato codex, mas que nem por isso há de ser menos legítima e nem menos passível de partilha, como nos ensina, mais uma vez, Antônio Vieira:

O livro é a mais perfeita imagem de seu autor, tão perfeita, que não se distingue dele, nem tem outro nome; o livro, visto por fora, não mostra nada; por dentro está cheio de mistérios; o livro, se se imprimem muitos volumes, tanto tem um como todos, e não tem mais todos que um; o livro está juntamente em Roma, na Índia e em Lisboa, e é o mesmo; o livro, sendo o mesmo para todos, uns percebem dele muito, outros pouco, outros nada; cada um conforme a sua capacidade: o livro é um mudo que fala, um surdo que responde, um cego que guia, um morto que vive, e não tendo ação em si mesmo, move os ânimos e causa grandes efeitos. Quem há que não reconheça em todas estas propriedades o Santíssimo Sacramento do altar? Livro é, e livro com grande propriedade: Comede volumen istud. ${ }^{7}$

\section{Comei este volume. Muito obrigado.}

\section{NOTAS}

1. Devo e agradeço essa constatação a Marcelo Dias de Carvalho, professor do curso de biblioteconomia do Centro Universitário Assunção/Unifai, São Paulo (SP).

2. Para um panorama a respeito, ver Jorge Luiz Antonio, "Sobre a poesia digital" (disponível em: <http://www.arteonline.arq.br/museu/ensaios/ ensaiosantigos/jlantonio.htm>). Ver também Cristiano de Sales, "Tentando compreender o poético nas criações digitais", Hipertextus Revista Digital (disponível em: <http://www.hipertextus.net/volume4/Cristiano-de-SALES. pdf $>$ ), e Alckmar Luiz dos Santos, “Como ler palavra na literatura digital”, in: Maria Clara Castellões de Oliveira \& Verônica Lucy Coutinho Lage (Org.), Literatura, crítica, cultura, Juiz de Fora, Editora UFJF, 2008.

3. Título do documentário de Mônica Simões (Brasil, 2005, cor, 55’) sobre como os entrevistados - pessoas de idades, escolaridades e classes sociais diferentes da região metropolitana de São Paulo - usam de seu tempo de lazer.

4. Pesquisa sobre "hábitos culturais do brasileiro" realizada anualmente pela Federação do Comércio do Rio de Janeiro, em parceria com a consultora 
Ipsos (disponível em: <http://www.fecomercio-rj.org.br/publique/media/ Pesquisa\%20de\%2oCultura.pdf $>$ ), revelou que, em 2013, 35\% dos sete mil entrevistados em 70 cidades (incluindo nove regiões metropolitanas) leram ao menos um livro naquele ano. Desde 2007, foi o índice mais alto aferido pela enquete, que em 2009 registrou o percentual mais baixo: $23 \%$. A metodologia da pesquisa não foi explicitada, o que recomenda cautela ao considerar seus resultados. Não se sabe a faixa etária, o grau de escolaridade e a classe social dos entrevistados - fatores elementares para uma análise mais precisa -, nem como e onde eles foram abordados ou se as questões apresentavam respostas de múltipla escolha ou eram abertas. Seria decisivo saber também o que os entrevistados entendem por "livro", distinguindo o eletrônico do impresso. De todo modo, a investigação é um indicativo a considerar.

5. Lançado em 2007, esse premiado documentário me parece essencial para quem quer compreender o universo cultural, as utopias (ou a ausência delas), as angústias, os valores da juventude contemporânea brasileira sem ignorar as cisões de classe tão típicas de nossa sociedade. O depoimento da professora encontra-se a partir de o:41:56 do filme, cuja íntegra está disponível em: < http://www.youtube.com/watch?v=g5W7mfOvqmU $>$.

6. Exceto as referências aos escritos de Hipácia, as demais foram extraídas de partes de duas versões diferentes do documentário apresentado pelo astrônomo norte-americano Carl Sagan, Cosmos (disponíveis em: <https://www. youtube.com/watch?v=JNKyEVtIfjE $>$ e em <https://www.youtube.com/ watch? $\mathrm{v}=\mathrm{u}$ _UcJiINkE $>$ ). Sobre Hipácia, ver Cristiane Monteiro de Oliveira, A presença das mulheres nas ciências exatas (Trabalho de conclusão de curso apresentado à graduação em matemática da Unesp), Guaratinguetá, mimeo., 2013, p. 18-9. (Disponível em: <http://base.repositorio.unesp.br/ handle/11449/120256>)

7. A. Vieira, "Sermão de Nossa Senhora de Penha de França, na sua igreja e convento da sagrada religião de Santo Agostinho" [1652]. (Disponível em: < http://www.usp.br/cje/anexos/pierre/padreantoniov.pdfs)

\section{Referências}

BARATIN, Marc. Da biblioteca à gramática: o paradigma da acumulação. In: \& JACOB, Christian (Dir.). O poder das bibliotecas: a memória dos livros no Ocidente. Tradução Marcela Mortara. Rio de Janeiro: Editora da UFRJ, 2000, p. 227-33.

BORGES, Jorge Luis. A biblioteca de Babel. In: __. Obras completas. Tradução Carlos Nejar. 3. reimp. São Paulo, Globo, 1999, v. 1, p. 516-23.

BOSI, Alfredo. Dialética da colonização. 3. reimp. São Paulo: Companhia das Letras, 1993.

BOTELHO, Isaura. Os públicos da cultura: desafios para as políticas culturais, Revista Observatório Itaú Cultural, São Paulo, 12, p. 9, maio/ago. 2011. Disponível em:<http://d3nvijy4u7zmsc.cloudfront.net/wp-content/uploads/itau_ pdf/oo1829.pdf>. Acesso em: 8 jun. 2015.

CHAUIÍ, Marilena. Convite à filosofia, 14. ed. São Paulo: Ática, 2012.

DARNTON, Robert. O poder das bibliotecas, Folha de S. Paulo, 15 abr. 2001, "Mais!". Disponível em: < http://wwwi.folha.uol. com.br/fsp/mais/fs1504200105.htm>. Acesso em: 8 jun. 2015. 
FISCHER, Steven Roger. História da leitura. Tradução Claudia Freire. São Paulo: Editora da Unesp, 2006.

GARCÍA Canclini, Néstor. Leitores, espectadores e internautas. Tradução Ana Goldberger, São Paulo: Iluminuras, 2008.

HANSEN, João Adolfo. O que é um livro? São Paulo: SESCSP, 2013.

JACOB, Christian. "Ler para escrever: navegações alexandrinas". In: BARATIN, Marc \&__ (Dir.). O poder das bibliotecas: a memória dos livros no Ocidente. Tradução Marcela Mortara. Rio de Janeiro: Editora da UFRJ, 2000, p. 227-33.

MILANESI, Luís. A casa da invenção: biblioteca, centro de cultura. 3. ed. São Paulo: Ateliê, 2003.

PETIT, Michèle. Os jovens e a leitura: uma nova perspectiva. Tradução Celina Olga de Souza. 2. ed. São Paulo: Editora 34, 2013.

VIEIRA, Antônio. Sermão de Nossa Senhora de Penha de França, na sua igreja e convento da sagrada religião de Santo Agostinho [1652]. Disponível em:< http://www.usp.br/cje/ anexos/pierre/padreantoniov.pdf $>$. Acesso em: 8 jun. 2015. .Sermões. (Org). Alcir Pécora. São Paulo: Hedra, 2000 , t. 1.

Recebido em: 10/o6/15

Aceito em: 01/08/2015

\footnotetext{
JOACI PEREIRA FURTADO

joacifurtado@id.uff.br

Graduado em história pela Universidade Federal de Ouro Preto, é mestre e doutor em história social pela USP. Foi editor de literatura e ensaio da Globo Livros e criador dos selos de literatura Tordesilhas e Tordesilhinhas. Hoje é professor dos cursos de Arquivologia e Biblioteconomia da Universidade Federal Fluminense. É autor de Uma república de leitores (Hucitec) e organizou edição das Cartas chilenas, de Tomás Antônio Gonzaga (Companhia das Letras).
} 